\title{
Evidence for the powerful catalytic ability of imidozirconocene complex from its epoxide ring cleavage reactions - A DFT mechanistic view ${ }^{\#}$
}

\author{
DHURAIRAJAN SENTHILNATHAN, RAJADURAI VIJAY SOLOMON and \\ PONNAMBALAM VENUVANALINGAM*
}

School of Chemistry, Bharathidasan University, Tiruchirappalli 620 024, India

e-mail: venuvanalingam@yahoo.com

\begin{abstract}
Imidozirconocene complex is known for its bifunctional reactivity and catalytic ability and this complex mediates ring cleavage of epoxides. Cyclooctene oxide (1) Norbornene oxide (2) and 2,5-dimethyl cyclohexene oxide (3) undergo ring cleavage in the presence of imidozirconocene complex. Epoxide $\mathbf{1}$ has accessible $\beta$-hydrogens (type I) while epoxide $\mathbf{2}$ and $\mathbf{3}$ do not have them (type II). Normally type I epoxides undergo elimination while type II epoxides prefer insertion. All the insertion reactions lead to five-membered metallacycle formation and elimination results in thermodynamically stable allyl-alkoxy product. The insertion is a two-step process following either diradical or zwitterionic pathway, while elimination is a one-step concerted reaction. DFT (density functional theory) modelling of these reactions at B3LYP/LANL2DZ level show that epoxide 1 undergoes elimination in agreement with experiment. However, calculations indicate that epoxide (2) proceeds through diradical intermediate in contrast to experimental observations. Surprisingly, epoxide (3) that has both the $\beta$ positions blocked by methyl groups undergoes elimination rather than insertion. AIM and EDA analyses offer further insights on the reaction mechanism and bifunctional reactivity of imidozirconozene complex.
\end{abstract}

Keywords. Imidozirconocene complex; epoxide ring cleavage reaction; density functional theory; AIM analysis.

\section{Introduction}

Imidometal complexes attract a lot of interest in recent years due to their potential applications in organic and inorganic transformations. ${ }^{1-4}$ In particular, imidozirconocene complexes (IZC) are known for their high reactivity and wider participation in a variety of reactions. ${ }^{5-7}$ The epoxide ring opening reactions especially the imidozirconocene mediated ring cleavage of epoxides opened up a fascinating field in organic synthesis. ${ }^{8-12}$ Robert $G$ Bergman is a pioneer in this field and has studied several such reactions. ${ }^{13,14}$ Another interesting feature observed in the imidozirconocene epoxide complex is the donation of the lone pair of epoxide oxygen to the metal centre which leads to the formation of a coordinate bond between the oxygen atom and the zirconium metal. In all these epoxide ring cleavage reactions, the IZC shows bifunctional reactivity where the zirconium acts as a Lewis acid and initiates the reaction and in the end, it acts as a Lewis base and completes the reaction. ${ }^{15-18}$ Experimental reports show that epoxides with accessible $\beta$-hydrogens (type I) undergo elimination while those without accessible $\beta$-hydrogens

\footnotetext{
\# Dedicated to Prof. N Sathyamurthy on his 60th birthday

*For correspondence
}

(type II) prefer insertion. In general, all the elimination reactions lead to the stable allyl-alkoxy product whereas insertion reactions lead to five-membered metallacycle product. The insertion reaction is a two-step reaction and the reaction is initiated by the cleavage of $\mathrm{C}_{\alpha}-\mathrm{O}$ bond homolytically or heterolytically leading to diradical or zwitterionic intermediates respectively, whereas elimination is a one-step concerted reaction. Though several experimental reports are available, the mechanistic details of these ring cleavage reactions of epoxides by IZC are scarce. An attempt has been made to understand the mechanism and the role of IZC in these reactions by our group recently. ${ }^{19}$ In the present work, the IZC mediated reactions of three epoxides have been modelled and results are compared with available experimental evidences.

\section{Computational details}

All calculations were performed at B3LYP/LANL2DZ level using Gaussian03 suite of programs. ${ }^{20-24}$ All stationary points on the potential energy surface were characterized by vibrational frequency analysis. All transition states have one imaginary frequency and minima have all real frequencies. In addition to that, 
Noodleman's broken symmetry (BS) formalism ${ }^{25-27}$ has been adopted to check the stability of the corresponding diradical species in the diradical pathway using 'STABLE $=$ OPT' keyword implemented in Gaussian03. ${ }^{20}$

EDA (Energy Decomposition Analysis) has been performed using the Amsterdam Density Functional (ADF 2007) package to analyse the existing bonding interactions between the $\mathrm{Cp}_{2} \mathrm{Zr}=\mathrm{N}-t-\mathrm{Bu}$ and the epoxide part in the IZC. ${ }^{28-37}$ The interaction energy is given by

$$
\Delta E_{\text {int }}=\Delta E_{\text {elestat }}+\Delta E_{\text {Pauli }}+\Delta E_{\text {orb }}
$$

where $\Delta E_{\text {elestat }}$ is the electrostatic interaction or contribution towards the bonding interactions. $\Delta E_{\text {Pauli }}$ gives Pauli's repulsion energy between occupied orbitals of the two fragments and $\Delta E_{\text {orb }}$ furnishes the total orbital contribution or covalent contribution towards the bonding.

Topological analysis has been performed using AIM2000 package ${ }^{38}$ to obtain further insights into the bonding situations in TS's and intermediates.

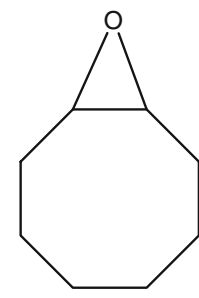

1

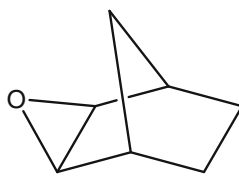

2

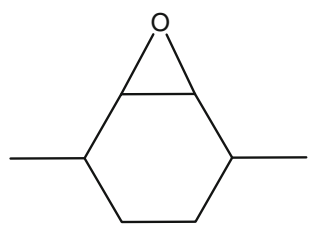

3
Figure 1. The chosen epoxides (1-3) for modelling the ring cleavage mediated by IZC.
The necessary wave functions have been generated at B3LYP/LANL2DZ level using Gaussian03.

\section{Results and discussion}

Three epoxides have been chosen here and epoxide 1 (cyclooctene oxide) has accessible $\beta$ hydrogen (type I) and epoxides 2 and 3 (norborene oxide and 2,5dimethyl cyclohexene oxide) do not have it (type II) (figure 1). The IZC exists as a coordination complex with tetrhydrofuran (THF) group in THF solution. The greater oxophilicity of epoxides over the THF group leads to the easy replacement of the THF group of IZC by epoxides even at milder condition. ${ }^{14}$ Therefore, the calculations were performed by taking imidozirconocene epoxide complex as the reactant. The general mechanism of imidozirconocene mediated epoxide ring cleavage reactions is presented in scheme 1 . It can undergo either elimination or insertion. The insertion proceeds either through zwitterionic or radical pathway and forms metallacycle product. Since each epoxide follows different mechanism, epoxides 1, 2 and 3 are discussed one by one in the following section.

\subsection{Cyclooctene oxide (1)}

The ring cleavage of cyclooctene oxide mediated by IZC is shown in scheme 2. Experiments show that cyclooctene epoxide follow elimination reaction readi$1 y^{14}$ and therefore elimination reaction and zwitterionic pathway of the insertion reaction have been modelled at B3LYP/LANL2DZ level and the energy

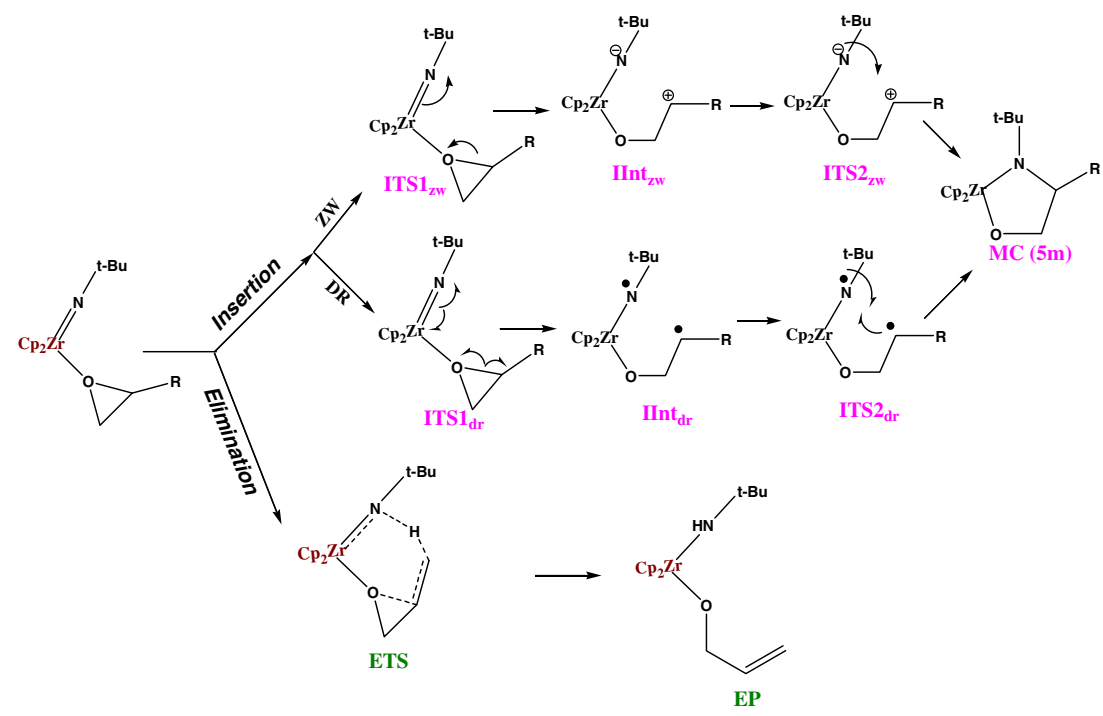

Scheme 1. General mechanism for both insertion and elimination reactions of epoxide ring cleavage mediated by IZC. 


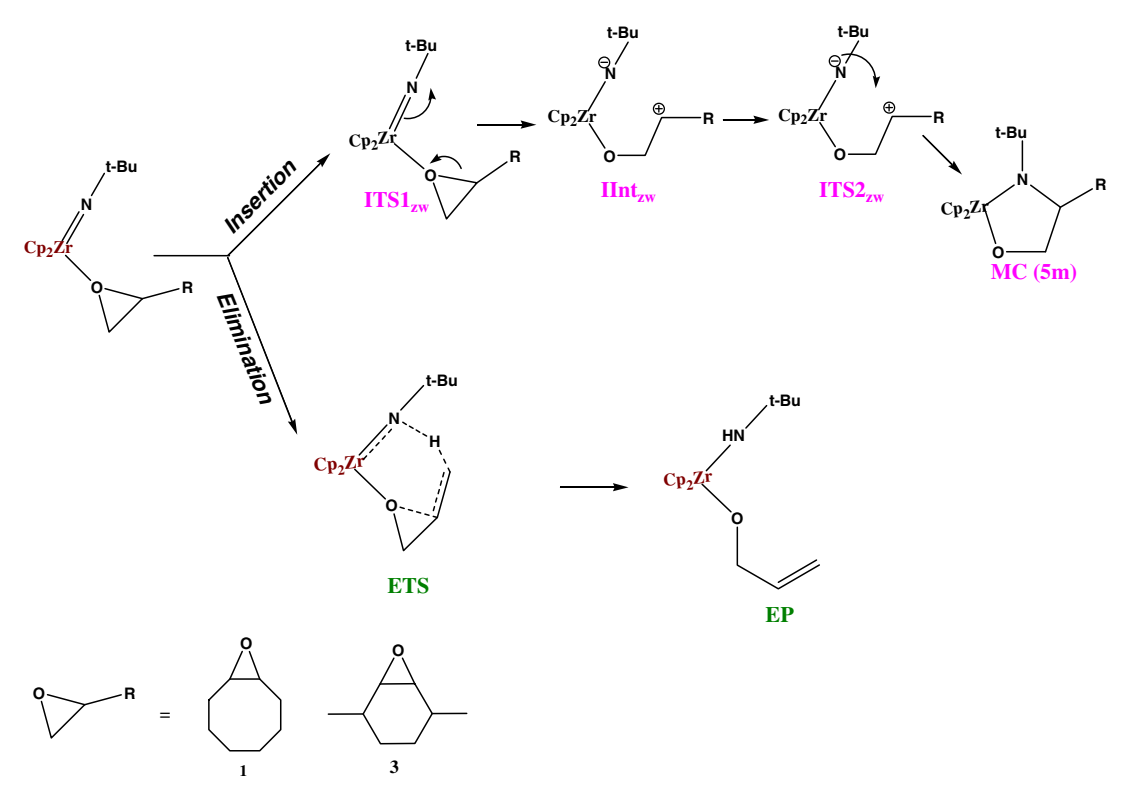

Scheme 2. Mechanism for both insertion and elimination reactions of epoxide ring cleavage of cyclooctene oxide and 2,5-dimethyl cyclohexene oxide mediated by IZC.

profile is given in figure 2. The elimination is found to be both kinetically and thermodynamically more favourable $\left(\Delta \mathrm{G}^{\ddagger}=9.32 \mathrm{kcal} / \mathrm{mol}\right)$ compared to insertion $\left(\Delta \mathrm{G}^{\ddagger}=25.64 \mathrm{kcal} / \mathrm{mol}\right)$. The elimination is a concerted single-step reaction where the breaking of $\mathrm{C}_{\alpha}-\mathrm{O}$ bond and the making of $\mathrm{N}-\mathrm{H}$ bond occurs simultaneously. The acidic nature of the $\beta$ hydrogen is more readily obstructed by the basic imido nitrogen and thus the reaction leads to the formation of an ally-alkoxy product.

\subsection{Norbornene oxide (2)}

Experimental report shows that on ring cleavage, the norbornene epoxide undergoes insertion alone and further, it may proceed via either carbon bridged nonclassical zwitterionic or through non-bridged classical diradical pathway. In this case, a conclusive evidence towards either of the mechanism from experiments is lacking. While experiments could not trap the zwitterion formed from the rearrangement, only an indirect

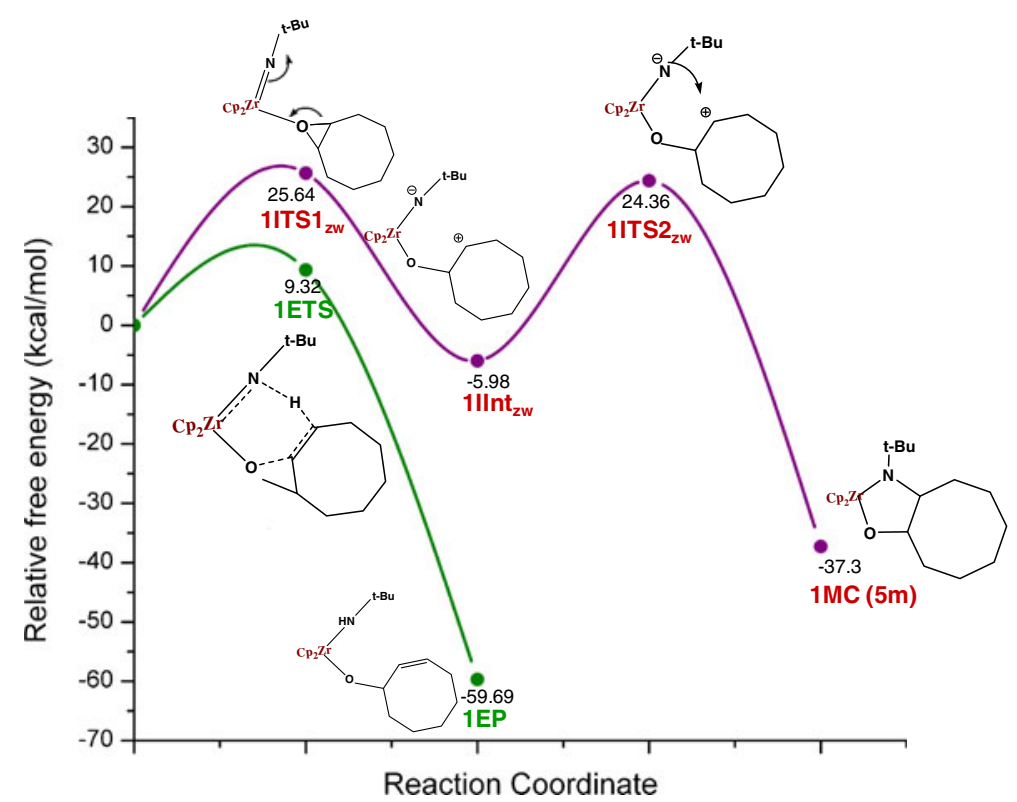

Figure 2. Free energy profile for the ring cleavage of cyclooctene oxide mediated by IZC at B3LYP/LANL2DZ. 


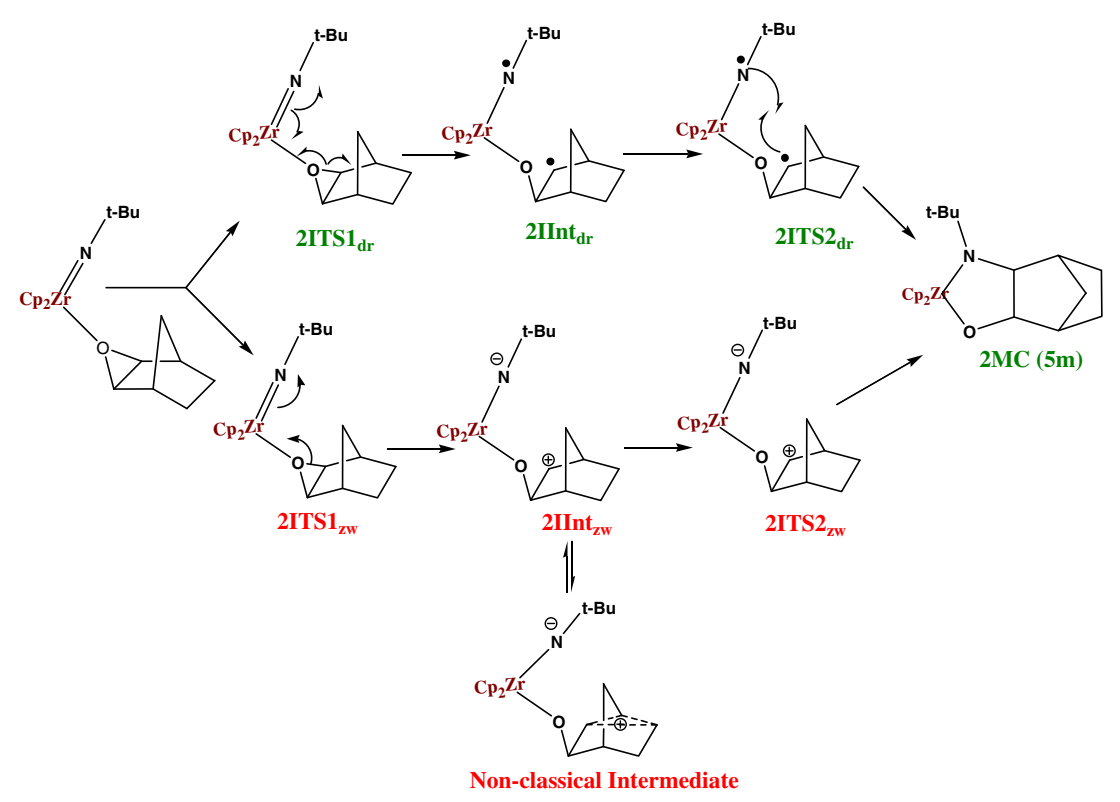

Scheme 3. The mechanism for both diradical as well as zwitterionic pathways of norbornene oxide ring cleavage reactions of IZC.

evidence through kinetics in favour of zwitterionic pathway was proposed. Hence, both the pathways have been modelled. The overall mechanism for this reaction is described in scheme 3 . From the computed energy profile (figure 3), it is clear that epoxide 2 predominantly follows diradical pathway over zwitterionic pathway with a very narrow energy variation which is contradictory to experimentally proposed zwitterionic pathway. Implicit and explicit inclusion of solvent does not stabilize the zwitterionic path as expected. DFT calculations with M06 functional also confirmed the earlier trend that the diradical path is low lying. These things could not clearly resolve the mechanism. Therefore, further experimental probe or calculations may lead to fruitful conclusions.

\subsection{2,5-Dimethyl cyclohexene oxide (3)}

In the case of 2,5-dimethyl cyclohexene oxide (3), both elimination as well as insertion have been monitored (figure 4) and for the insertion reaction only the zwitterionic path has been followed. Cleavage of this epoxide has not been experimentally studied yet, but this epoxide has been chosen particularly for the reason that both the $\beta$ positions were blocked by methyl group. Under

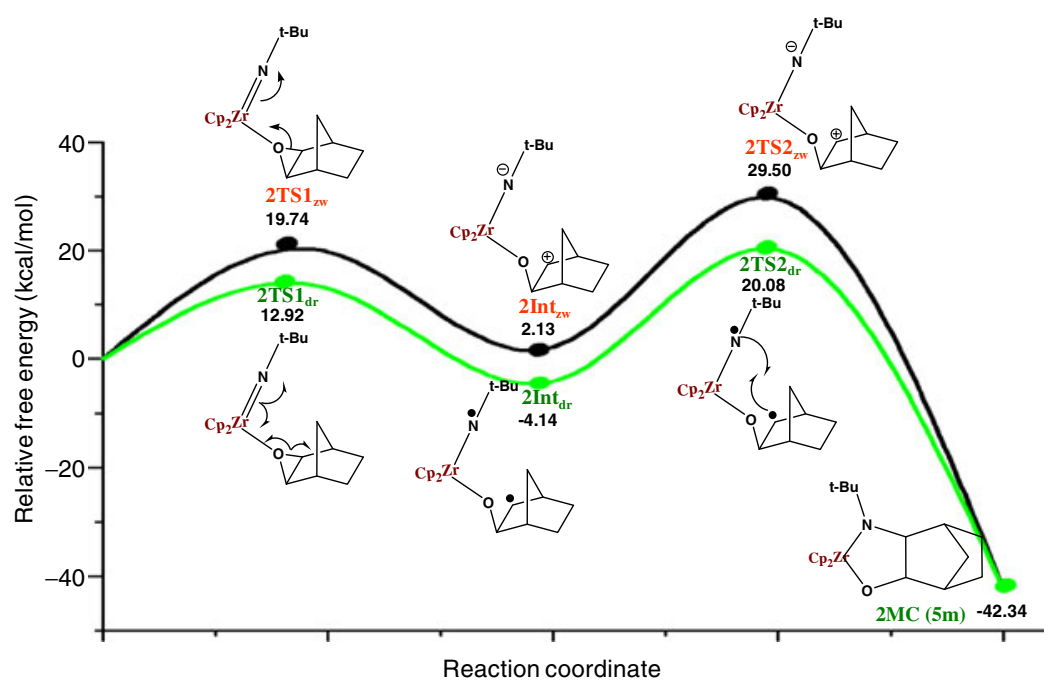

Figure 3. Free energy profile for the ring cleavage of norbornene oxide mediated by IZC at B3LYP/LANL2DZ. 


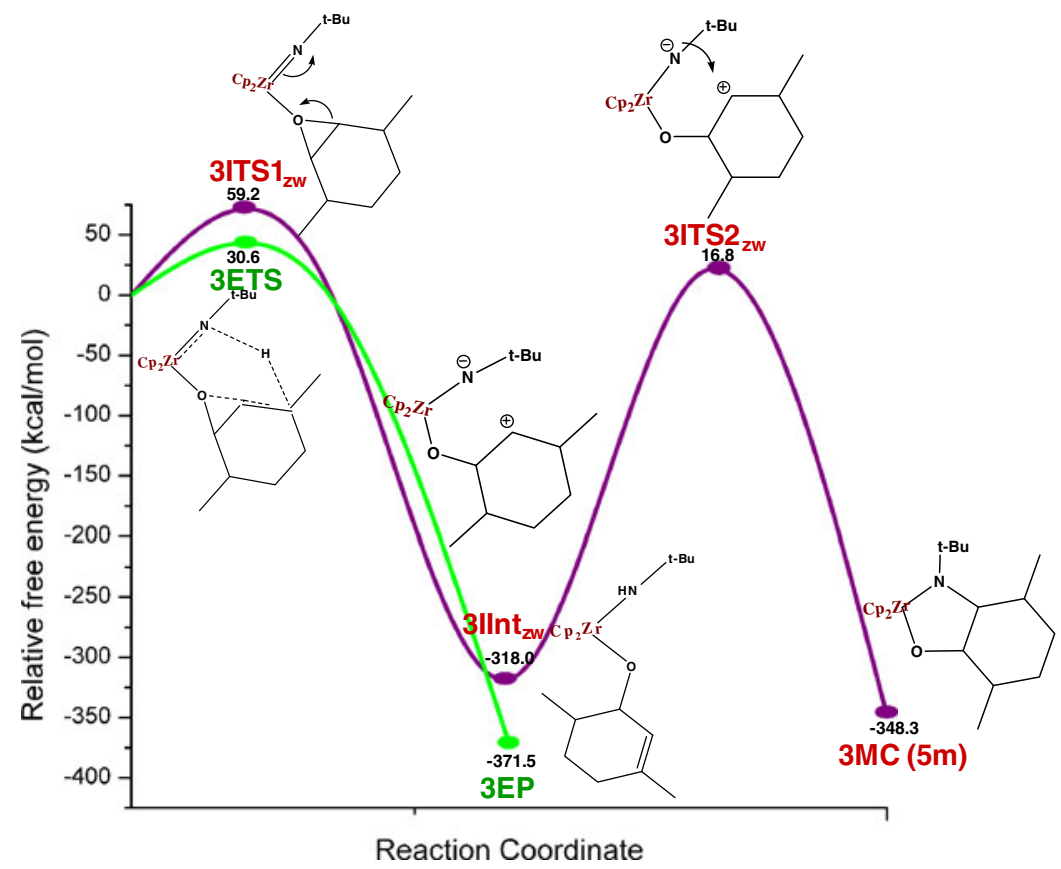

Figure 4. Free energy profile for the ring cleavage of 2,5-dimethyl cyclohexene oxide mediated by IZC at B3LYP/LANL2DZ.

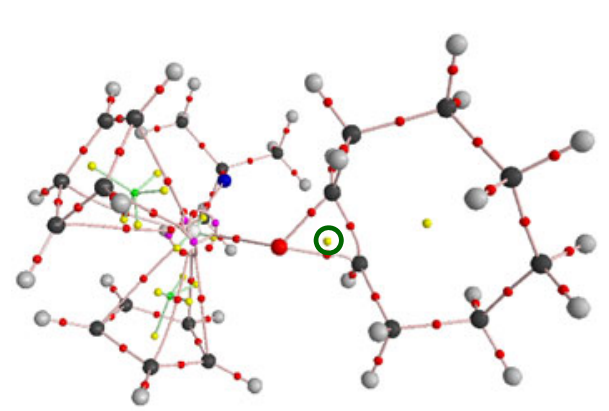

1RC

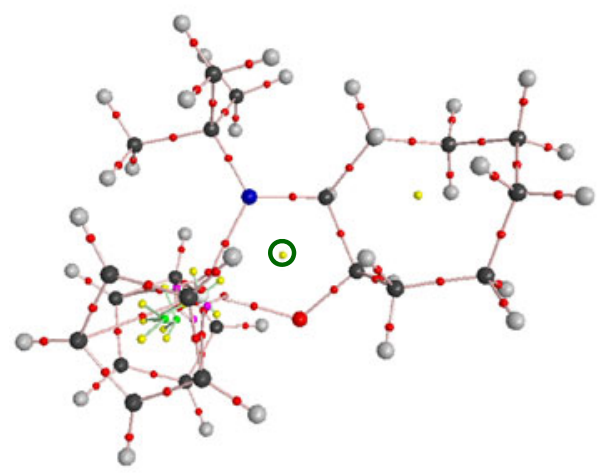

1ITS2

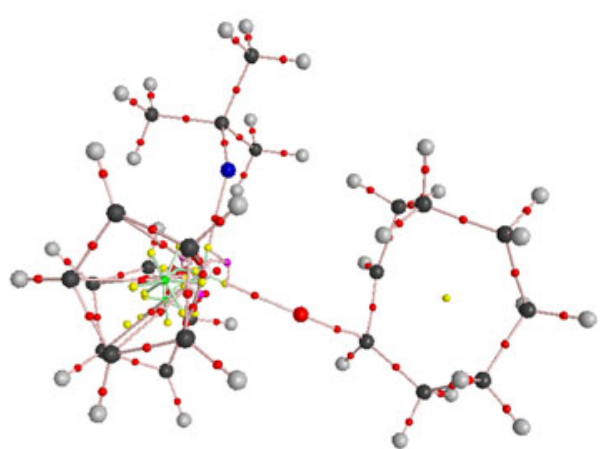

1ITS1

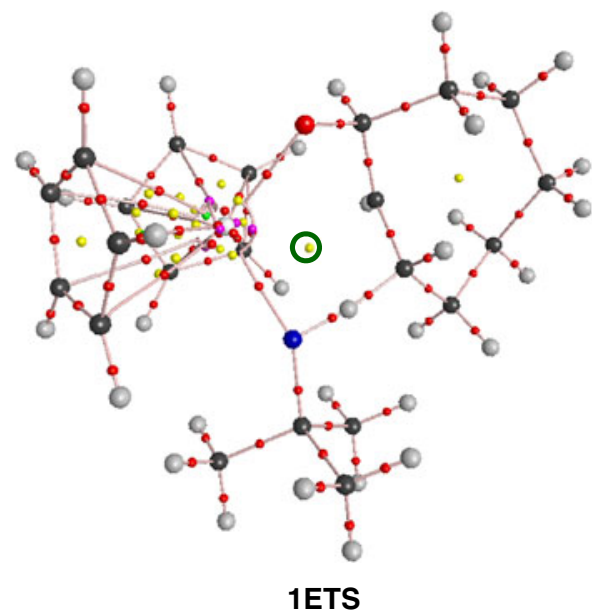

Figure 5. The molecular graph of reactant $(\mathrm{RC})$, insertion transition states $\left(\mathrm{ITS} 1_{\mathrm{zw}}\right.$ and ITS $2_{\mathrm{zw}}$, insertion intermediate ( $\left.\mathrm{IInt}_{\mathrm{zw}}\right)$ and elimination transition states (ETS) for all the epoxides along with its BCPs like bond critical point (red), ring critical point (yellow) and cage critical point (green) are shown. 
such conditions normally, the molecule is expected to go insertion. Surprisingly, our calculations reveal that 2,5-dimethyl cyclohexene oxide follow elimination over insertion (figure 4). From the profile, it is clear that elimination is favoured both thermodynamically and kinetically than insertion reaction; the concerted TS is low lying by $28.6 \mathrm{kcal} / \mathrm{mol}$ over insertion TS. The main factor that lowers the elimination path is the formation of very stable tertiary carbocation fragment in the 3ETS on the reaction path and the formation is facilitated by the easy removal of acidic $\beta$ hydrogen. Thus epoxide 3 follows elimination reaction preferably over insertion.

\subsection{AIM analysis}

The AIM approach is based on the topological properties of the electron density denoted by $(\rho)$ which is used to examine the bonding interactions present in various chemical systems. ${ }^{39-42}$ The topological analysis have been carried out on the optimized geometries of the reactant complexes, transition states and intermediates of all the epoxides studied here, using AIM analysis at B3LYP/LANL2DZ level. According to Bader, the presence of a $(3,-1)$ bond critical point $(\mathrm{BCP})$ along the bond path is accepted as the standard criterion for the existence of all types of bonding and non-bonding interactions.

In general, the $(3,+1)$ RCP indicates that the existence of a ring structure and the $(3,-1) \mathrm{BCP}$ indicates the existence of a bond between two corresponding atoms. Molecular graph of reactant complex $(\mathrm{RC})$, transition states $\left(\mathrm{ITS} 1_{\mathrm{zw}}\right.$ and ITS $2_{\mathrm{zw}}$ ) and ETS is presented in figure 5 and the bond critical points $(3,-1$; BCPs), ring critical points $(3,+1$; RCPs), and cage critical points $(3,+3$; CCPs $)$ are represented as small circle of red, yellow and green colour, respectively. The computed topological properties at $\mathrm{Zr}-\mathrm{O}$ bond critical point are given in table 1.

The presence of $(3,+1)$ RCPs indicated by a dark green circle in reactant, TS2 and ETS indicates the closed ring nature of the species and their absence in TS1 supports the ring cleavage step. Similarly, all TS2 species are confirmed by the presence of $(3,-1)$ BCP between the imido nitrogen and $\mathrm{C}_{2}$ carbon and moreover, the appearance of $(3,+1) \mathrm{RCP}$ confirms the formation of five-membered ring in this mechanism.

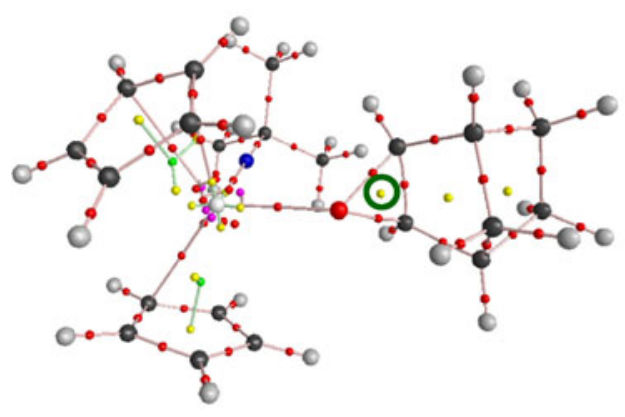

2RC

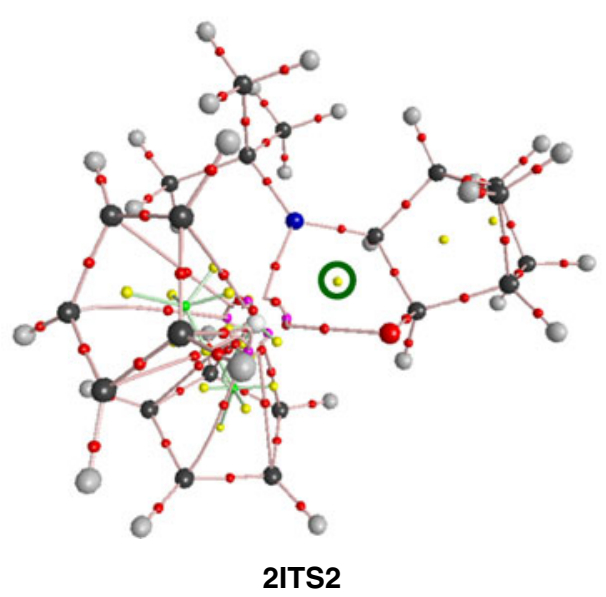

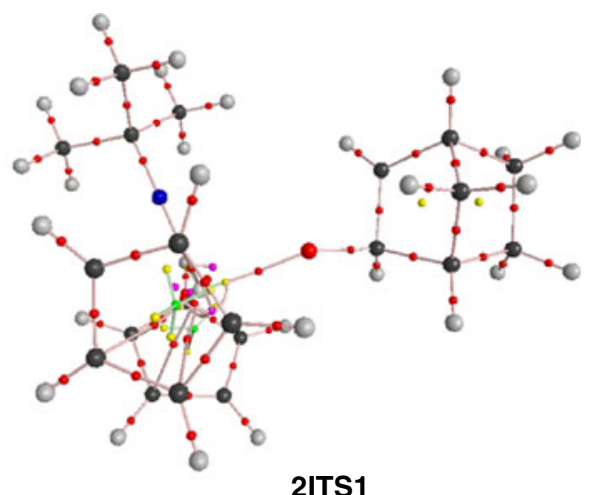

2ITS1

Figure 5. (continued). 


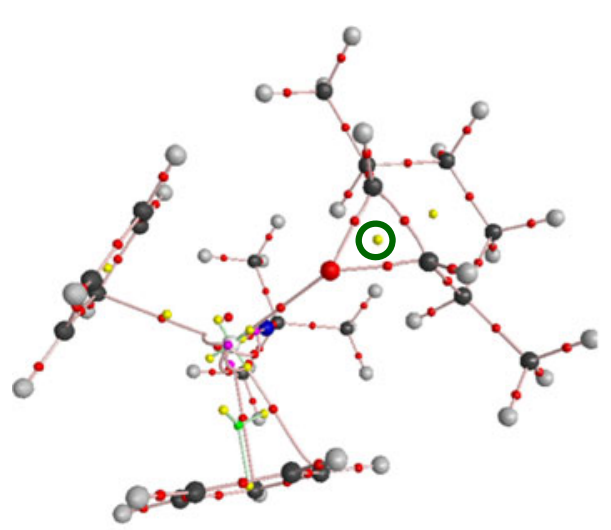

3RC

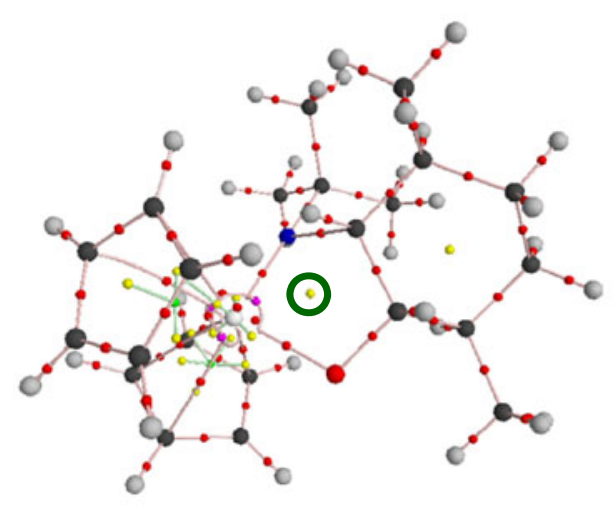

3ITS2

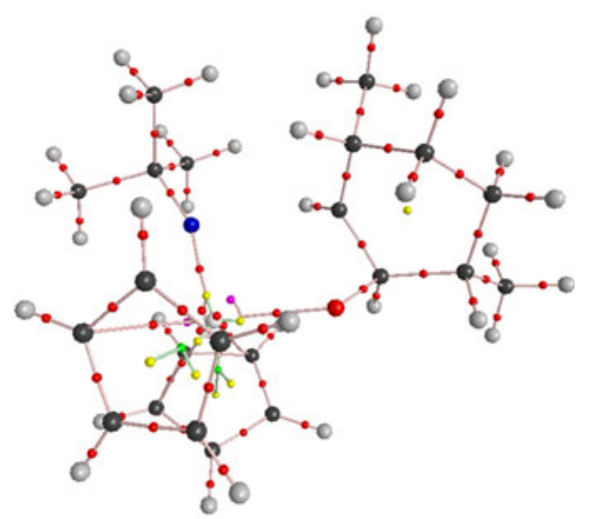

3ITS1

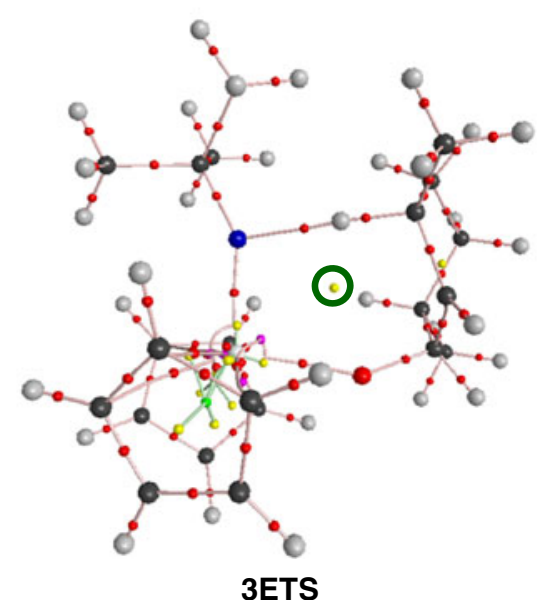

Figure 5. (continued).

AIM framework further offers excellent evidences for the conversion of $\mathrm{Zr}-\mathrm{O}$ coordinate bond to $\mathrm{Zr}-\mathrm{O}$ covalent bond during the course of the reaction. The calculated $\rho_{\text {bcp }}$ and $-\nabla^{2} \rho_{\text {bcp }}$ values at $\mathrm{Zr}-\mathrm{O}$ BCP (table 1) clearly reveals that the existence of $\mathrm{Zr} \leftarrow \mathrm{O}$ bond in all the reactant complexes as its $-\nabla^{2} \rho$ value lies around -0.06 and the domination of eigen values of Hessian $\lambda 3$ (0.37) compared to $\lambda 1(-0.06)$ and $\lambda 2(-0.06)$ at this critical point further support the existence of coordinate bond $(\mathrm{O} \leftarrow \mathrm{Zr})$ between $\mathrm{O}$ and $\mathrm{Zr}$ in all the reactants. At the same time, the same $\mathrm{Zr}-\mathrm{O} \mathrm{BCP}$ in all the intermedi- ates possess a lower $-\nabla^{2} \rho$ value compared to that in the reactant complexes suggesting the conversion of coordinate to covalent bond. Similarly, the eigen values of Hessian also reflect the covalent bond conversion trend $(\lambda 1 \approx \lambda 2>\lambda 3)$ in all the intermediates as well as in the ETS's.

The Laplacian of electron density contour maps as well as corresponding gradient vector field trajectories are shown in figure 6 and it clearly explains the ring cleavage step as well as the ring closing process. In the TS1, the charge depletion between the $\mathrm{C}_{\alpha}$ and the

Table 1. Calculated bond critical properties of $\mathrm{Zr}-\mathrm{O}$ bond in $\mathrm{RC}$, Int and ETS for all the epoxides.

\begin{tabular}{lcccccc}
\hline Epoxide & species & $\rho$ & $-\nabla^{2} \rho$ & $\lambda_{1}$ & $\lambda_{2}$ & $\lambda_{3}$ \\
\hline $\mathbf{1}$ & 1RC & 0.048601 & -0.06455 & -0.06116 & -0.05495 & 0.37435 \\
& 1IIntZW & 0.092204 & -0.092249 & -0.13784 & -0.12252 & 0.62937 \\
& 1ETS & 0.094906 & -0.090118 & -0.1452 & -0.12316 & 0.62937 \\
$\mathbf{2}$ & 2RC & 0.047592 & -0.064227 & -0.0595 & -0.05370 & 0.37020 \\
& 2IInt & 0.106131 & -0.137543 & -0.1487 & -0.14103 & 0.83998 \\
$\mathbf{3}$ & 3RC & 0.046240 & -0.063270 & -0.0575 & -0.04974 & 0.36035 \\
& 3IInt & 0.106019 & -0.136858 & -0.1492 & -0.14107 & 0.83775 \\
& 3ETS & 0.076137 & -0.100410 & -0.1032 & -0.09243 & 0.59726
\end{tabular}



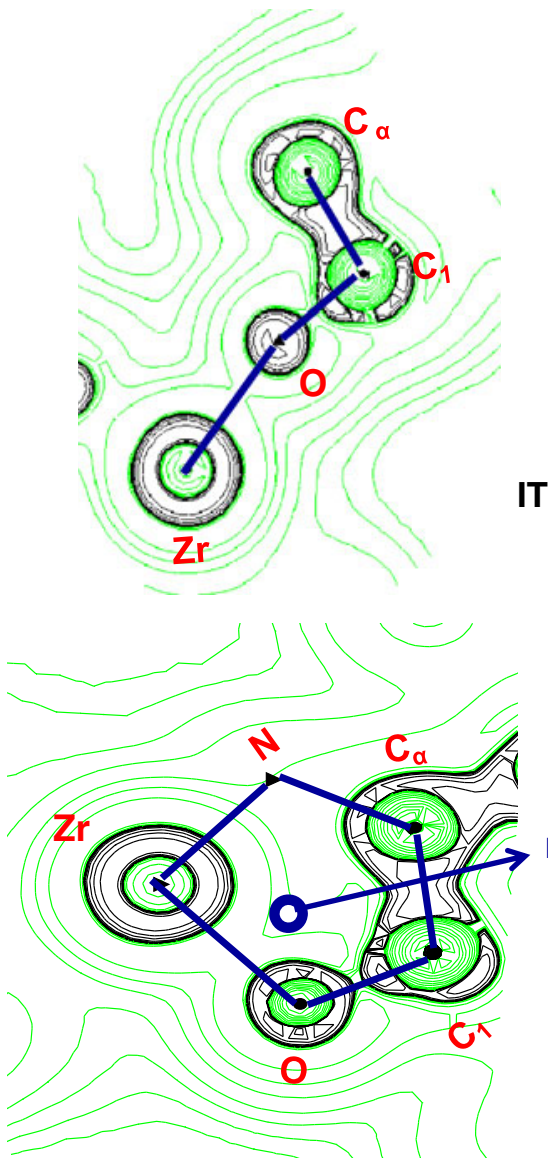

ITS1
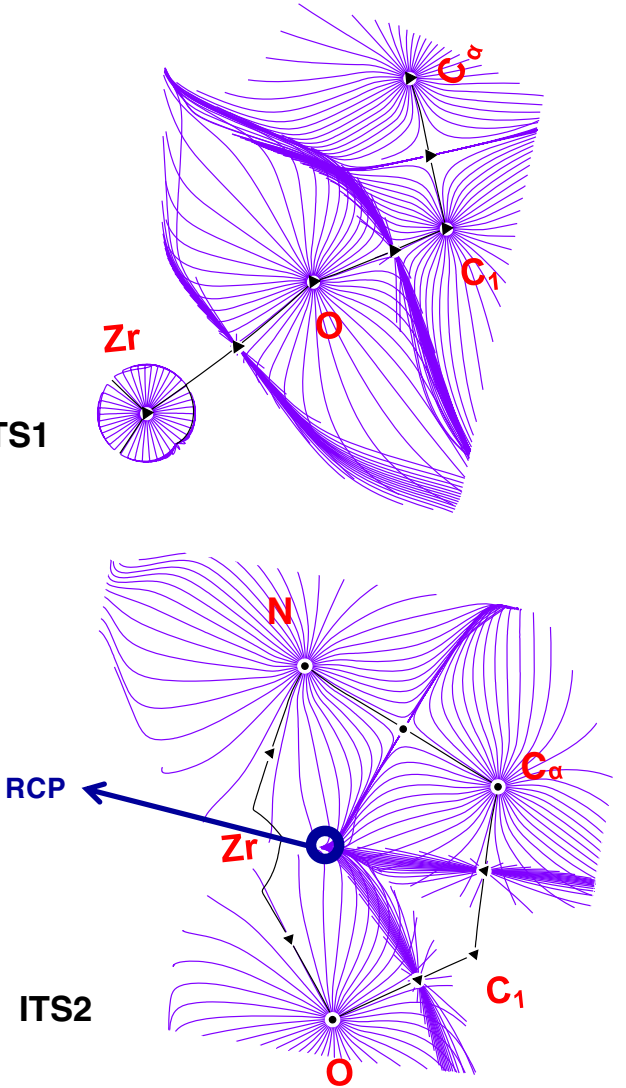

0

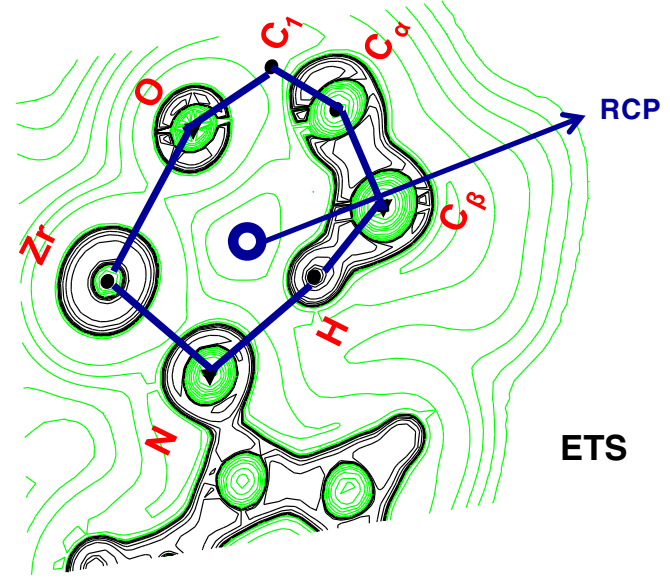

Figure 6. The contour maps of Laplacian of electron density (left) and corressponding gradient vector field of electron density (right) of insertion transition states $\left(\operatorname{ITS} 1_{\mathrm{zw}}\right.$ and $\operatorname{ITS} 2_{\mathrm{zw}}$, and elimination transition state (ETS) illustrating the bonding situations.

oxygen atom confirms the ring cleavage step. Moreover, the ring closure nature has been confirmed by the ring critical point in TS2 and ETS as shown in the figure.

\subsection{Energy decomposition analysis}

In these ring cleavage reactions IZC is known for its bifunctional reactivity. To gain additional insights into this bifunctional reactivity, EDA has been carried out by considering the $\mathrm{Cp}_{2} \mathrm{Zr}=\mathrm{N}-t$-Bu and epoxide as individual fragments. The computed interaction energies (table 2) $\Delta E_{\text {int }}$ indicate that the intermediate has greater interaction than that of the reactant complex. The resulting $\Delta E_{\text {elestat }}$ and $\Delta E_{\text {orb }}$ values reveal that the ionic interactions are predominant in the reactant complex whereas, covalent interactions play a crucial role in the intermediates. On the other hand, 
Table 2. Energy decomposition analysis at BP86/TZP of the reactants and intermediates of all the epoxides (1-3) and energies in $\mathrm{kcal} / \mathrm{mol}$; the value in parentheses gives the percentage contribution to the total attractive interactions $\left(\Delta E_{\mathrm{Elstat}}+\right.$ $\left.\Delta E_{\mathrm{Orb}}\right)$

\begin{tabular}{|c|c|c|c|c|c|c|}
\hline & \multicolumn{2}{|c|}{ Epoxide 1} & \multicolumn{2}{|c|}{ Epoxide $\mathbf{2}$} & \multicolumn{2}{|c|}{ Epoxide 3} \\
\hline & $1 \mathrm{RC}$ & 1Int & $2 \mathrm{RC}$ & 2Int & $3 \mathrm{RC}$ & 3 Int \\
\hline$\Delta \mathrm{E}_{\text {int }}$ & -43.62 & -89.32 & -18.84 & -126.99 & -18.00 & -127.60 \\
\hline$\Delta \mathrm{E}_{\text {orb }}$ & $-23.91(33.8 \%)$ & $-129.45(55.0 \%)$ & $-20.19(33.4 \%)$ & $-156.33(66.3 \%)$ & $-22.45(36.7 \%)$ & $-176.76(83.8 \%)$ \\
\hline$\Delta \mathrm{E}_{\text {pauli }}$ & 27.15 & 146.44 & 41.56 & 108.89 & 43.21 & 83.45 \\
\hline$\Delta \mathrm{E}_{\text {elstat }}$ & $-46.86(66.2 \%)$ & $-106.31(45.0 \%)$ & $-40.21(66.6 \%)$ & $-79.55(33.7 \%)$ & $-38.75(63.3 \%)$ & $-34.29(16.2 \%)$ \\
\hline$\Delta \mathrm{E}_{\text {elstat }} / \Delta \mathrm{E}_{\text {orb }}$ & 1.96 & 0.82 & 1.99 & 0.50 & 1.73 & 0.19 \\
\hline
\end{tabular}

Note: RC - Reactant complex and Int- intermediate

$\Delta E_{\text {elestat }} / \Delta E_{\text {orb }}>1$ implies that the bond is coordinate in nature, whereas $\Delta E_{\text {elestat }} / \Delta E_{\text {orb }}<1$ implies that the bond is of covalent nature. From the table 1, the $\Delta E_{\text {elestat }} / \Delta E_{\text {orb }}$ values show that in the reactant complex, the lone pair on the oxygen atom is donated to the vacant orbital of zirconium to form the $(\mathrm{Zr} \leftarrow \mathrm{O})$ coordinate bond and this bond is further converted into a full covalent bond in the intermediate. This formation of covalent bond brings the two fragments closer, as a result, $\Delta E_{\text {Pauli }}$ increases on moving from reactant to the intermediate.

\section{Conclusions}

The detailed mechanism of ring cleavage reaction of three different epoxides catalysed by imidozirconocene complex have been investigated using DFT calculations. The epoxide $\mathbf{1}$ follows elimination reaction more readily as observed in experiments. Though epoxide $\mathbf{2}$ and 3 do not have accessible $\beta$-hydrogens, each follows different pathways. Calculations clearly predict that epoxide 2 proceeds via diradical pathway over zwitterionic pathway. The epoxide $\mathbf{3}$ undergoes elimination than insertion, contrary to expectations, due to acidic nature of $\beta$-hydrogen which stabilizes the tertiary carbocation. AIM analysis provides enough evidence for the conversion of the $\mathrm{Zr} \leftarrow \mathrm{O}$ bond to $\mathrm{Zr}-\mathrm{O}$ bond along the reaction path and EDA also confirms the same trend.

\section{Acknowledgements}

The authors thank the refree for the helpful and suggestive criticism. PV and DS thank the Council of Scientific and Industrial Research (CSIR), India, for the financial support in the form of a major research grant (Ref. No. 02(2158)/07/EMR-II). RVS thanks the University Grants Commission (UGC), India for the financial support through Maulana Azad National Fellowship (Ref. No. F.40-17(C/M)/2009(SA-III/MANF).

\section{References}

1. Walsh P J, Hollander F J and Bergman R G 1988 J. Am. Chem. Soc. 1108729

2. Cummins C C, Baxter S M and Wolczanski P T $1988 \mathrm{~J}$. Am. Chem. Soc. 1108731

3. Cummins C C, Schaller C P, Van Duyne G D, Wolczanski P T, Chan A W E and Hoffmann R $1991 J$. Am. Chem. Soc. 1132985

4. Profilet R D, Zambrano C H, Fanwick P E, Nash J J and Rothwell I P 1990 Inorg. Chem. 294364

5. Schaller C P, Bonanno J B and Wolczanski P T 1994 J. Am. Chem. Soc. 1164133

6. Sweeney Z K, Salsman J L, Andersen R A and Bergman R G 2000 Angew. Chem. Int. Ed. 392339

7. Meyer K E, Walsh P J and Bergman R G 1995 J. Am. Chem. Soc. 117974

8. Bartoli G, Bosco M, Carlone A, Locatelli M, Massaccesi M, Melchiorre P and Sambri L 2004 Org. Lett. 6 2173

9. Larrow J F, Schaus S E and Jacobsen E N 1996 J. Am. Chem. Soc. 1187420

10. Caron M and Sharpless K B 1985 J. Org. Chem. 50 1557

11. Bergmeier S C 2000 Tetrahedron 562561

12. Ager D J, Prakash I and Schaad D R 1996 Chem. Rev. 96835

13. Blum S A, Walsh P. J and Bergman R G $2003 \mathrm{~J}$. Am. Chem. Soc. 12514276

14. Blum S A, Rivera V A, Ruck R T, Michael F E and Bergman R G 2005 Organometallics 241647

15. Hill M, Krker G, Kehr G, Frohlich R and Kataeva O 2004 J. Am. Chem. Soc. 12611046

16. Ichikawa E, Suzuki M, Yabu K, Albert M, Kanai M and Shibasaki M 2004 J. Am. Chem. Soc. 12611808

17. Kennedy-Smith J J, Nolin K A, Gunterman H P and Toste F D 2003 J. Am. Chem. Soc. 1254056

18. Eldred S E, Stone D A, Gellman S H and Stahl S S 2003 J. Am. Chem. Soc. 1253422

19. Senthilnathan D and Venuvanalingam P 2011 Eur. J. Inorg. Chem. 2842

20. Gaussian 03, Revision C.02, Frisch M J, Trucks G W, Schlegel H B, Scuseria G E, Robb M A, Cheeseman J R, Montgomery Jr J A, Vreven T, Kudin K N, Burant J C, Millam J M, Iyengar S S, Tomasi J, Barone V, Mennucci B, Cossi M, Scalmani G, Rega N, Petersson G A, Nakatsuji H, Hada M, Ehara M, Toyota K, Fukuda 
R, Hasegawa J, Ishida M, Nakajima T, Honda Y, Kitao O, Nakai H, Klene M, Li X, Knox J E, Hratchian H P, Cross J B, Bakken V, Adamo C, Jaramillo J, Gomperts R, Stratmann R E, Yazyev O, Austin A J, Cammi R, Pomelli C, Ochterski J W, Ayala P Y, Morokuma K, Voth G A, Salvador P, Dannenberg J J, Zakrzewski V G, Dapprich S, Daniels A D, Strain M C, Farkas O, Malick D K, Rabuck A D, Raghavachari K, Foresman J B, Ortiz J V, Cui Q, Baboul A G, Clifford S, Cioslowski J, Stefanov B B, Liu G, Liashenko A, Piskorz P, Komaromi I, Martin R L, Fox D J, Keith T, Al-Laham M A, Peng C Y, Nanayakkara A, Challacombe M, Gill P M W, Johnson B, Chen W, Wong M W, Gonzalez C and Pople J A 2004 Gaussian, Inc., Wallingford CT

21. Hay P J and Wadt J 1995 J. Chem. Phys. 822154

22. Bach M A, Parameswaran P, Jemmis E D and Rosenthal U 2007 Organometallics 262149

23. Jemmis E D, Phukan A K and Giju K T 2002 Organometallics 212254

24. Jemmis E D, Roy S, Burlakov V V, Jiao H, Klahn M, Hansen S and Rosenthal U 2010 Organometallics 2976

25. Noodleman L 1981 J. Chem. Phys. 745737

26. Noodleman L and Baerends E J 1984 J. Am. Chem. Soc. 1062316

27. Noodleman L, Peng C Y, Case D A and Mouesca J M 1995 Coord. Chem. Rev. 144199
28. De Velde G, Bickelhaupt F, Baerends E J, van Gisbergen S A J, Fonseca G C, Snijders J G and Ziegler T, $2001 \mathrm{~J}$. Comput. Chem. 22931

29. Guerra C F, Snijders J G, De Velde G and Baerends E, 1998 J. Theor. Chem. Acc. 99391

30. van Lenthe E, Baerends E J and Snijders J G 1994 J. Chem. Phys. 1019783

31. Amsterdam Density Functional, SCM.Vrije Universiteit, Amsterdam, The Netherlands (http://www.scm.com)

32. Lein M, Frunzke J, Timoshkin A, Frenking G and Lein M 2003 Inorg. Chem. 422504

33. Perdew J P, Burke K and Ernzerhof M 1996 Phys. Rev. Lett. 773865

34. van Lenthe E, Baerends E J and Snijders J G 1993 J. Chem. Phys. 994597

35. van Lenthe E, Ehlers A E and Baerends E J 1999 J. Chem. Phys. 1108943

36. Ziegler T and Rauk A 1977 Theor. Chim. Acta. 461

37. Morokuma K 1971 J. Chem. Phys. 551236

38. AIM2000 Biegler-König F W, Schönbohm, J and Bayles D 2001 J. Comput. Chem. 22545

39. Bader R F W 1990 Atoms in molecules - A quantum theory, New York: Oxford University Press

40. Bader R F W and Essén H 1984 J. Chem. Phys. 801943

41. Bader R F W 1991 Chem. Rev. 91893

42. Bader R F W 1998 J. Phys. Chem. A 1027314 